\title{
Web Based vs. Web Supported Learning Environment - A Distinction of Course Organizing or Learning Style?
}

\author{
Hong Wu \\ Østfold University College, Sarpsborg, Norway
}

\author{
hong.wu@hiof.no
}

\begin{abstract}
This paper describes an online course "Construction Engineering and Project Calculations", conducted by Østfold University College of Norway in 2002. The course was targeted to the college's engineering students, mainly on campus, with a possibility for off-campus course participants. It was intended to introduce online courseware (LearningSpace) as a learning tool for the course, and the students were encouraged to use LearningSpace as their basic learning tool. The course analysis indicated, however, their use of this courseware, only limited as a supportive tool, but not as a basic learning tool. The course observation also shows a factor that even for student online activities, the majority of online activities were concentrated on campus, within normal working days. Their main online activities are also categorized for assignments (duty based) with very little discussions (voluntary based). As a result, the course instructor had to conduct face-toface lectures fully as an ordinary teaching plan. The course conducting was rather defined as a web supported, not a web based learning environment.
\end{abstract}

Keywords: Web based or web supported environment, course organizing, learning style, and virtual classroom

\section{Introduction}

The debate of online teaching and practice has never been ceased since our university college introduced online solutions as an alternative teaching tool. Like other academic discussions, there is still no clear answer for this debate yet. There are always divided opinions for what is the best learning environment online, whether it was web based or web supported. It is likely an enthusiast will appreciate highly a web based learning environment and believe this will replace classrooms in the future. On the other hands, a traditionalist might be more careful to adopt a learning environment fully online, and it is likely that web supported option is more welcome here. However, the distinction between these two options is not always clearly made for learners, or even for instructors. This paper will describe a case of such online environment, and it will demonstrate the difference of web supportive and web based learning environment, throughout this case.

Material published as part of this journal, either on-line or in print, is copyrighted by Informing Science. Permission to make digital or paper copy of part or all of these works for personal or classroom use is granted without fee provided that the copies are not made or distributed for profit or commercial advantage AND that copies 1) bear this notice in full and 2) give the full citation on the first page. It is permissible to abstract these works so long as credit is given. To copy in all other cases or to republish or to post on a server or to redistribute to lists requires specific permission from the publisher at Publisher@InformingScience.org

\section{The Best Learning Environment - Web Based or Web Supported?}

Though many adopt and use web courseware as their new teaching 
tools, the definitions of web based and web supported practices are not always clarified and familiar for everyone. Not every user knows the difference between web based and web supported learning environments. Below is one common and popular definition that we used to distinguish the two environments:

- Web based learning environment - the majority, say, at the least 50\% of teaching and learning activities, for instance, discussions, questions, comments, and feedback evaluations are conducted through the web or web courseware.

- Web supported learning environment - the minority, say, less than $50 \%$ of mentioned activities are forwarded by the web or web courseware. Over a half part of mentioned teaching activities are dominated by traditionally face-to-face classroom teaching.

The crucial distinction is the volume of teaching and learning activities. There are several indicators that reflect such activities, for instance, a statistical summary of written documents by users, or their visiting frequencies in the virtual classroom, or their working hours online versus offline.

\section{The Case of Online Course for "Construction Engineer- ing and Project Calculations"}

As a pilot project of online teaching for on campus students, the course "Construction Engineering and Project Calculations" is was adopted online at Østfold University College in 2001. The course was also opened availably for off campus students, so that both on campus, off campus students and industrial professionals are able to follow the course at the same period. This opening was indeed a practice integrating the mentioned teaching services, on campus, off campus and professionals, together. It was a practical online approach for teaching activities (Selwood, Fung \& O'Mahony, 2003). The primary intention was extending the course accessibility for these different targeting groups, as objectives sound:

- Offering course participants, especially professionals, an opportunity to upgrading their competence and skills without absence from their daily work.

- Flexibility for the course participants, so that they are able to follow the lectures whenever and where they have Internet accesses.

In addition, there is also an intention for the university college to conduct such an online course to acquiring experience in this field.

The course was conducted online and accomplished for a class of 36 on campus engineering students, plus an external student from another university college (which is located approximately $500 \mathrm{~km}$ away) in early 2002. The entire course curriculum and related assignments, student project reports, course instructor's consulting and evaluations for these reports are adopted online, (Barrett, Levinson \& Lisanti, 2001) through a pre-selected courseware - Learning Space (IBM Lotus software, 2003). Combined with the course's major curriculum, there are other additional and optional reading materials available in the course's virtual classroom. These include 40 lecture books, few samples and cases, and a construction engineering case of Lærdal Tunnel (2000), the world longest road tunnel.

This organizing provides an opportunity for every student to follow the course, without necessarily face-to-face meetings. However, as an experiment and a pilot project, the course conductor still offered to give the traditional face-to-face lectures aside of his online teaching.

The course online adoption also stressed the following 3 aspects that focus on:

- The course is structured into few, interrelated but independent modules

- The selection of online solution for this course - Learning Space 
- The need of flexibility and accessibility

The structure of interrelated but independent modules provides openings for individuals, especially external participants, to take part one, two or all modules of the course, according to their needs. There are rooms for discussions, assignments/tasks and feedback, so the course was properly designed as an e-learning environment (Jain, Howlett, Ichalkaranje \& Tonfoni, 2002; Palloff \& Pratt, 2003).

The selection of online solution - Learning Space was based on few criteria such as availability for technical assistance, reasonable user fees and comprehensive functionalities. The last criterion is particularly important, since this courseware has few relevant functions to conduct process evaluations and data analysis, which are required for this project.

There have been quite few discussions about the suitability of online teaching for on campus students. The opinions are divided and there never seem to be a common answer for this debate. However, there is no doubt about the flexibility and accessibility that online solutions are able to offer, even for on campus students (Naidu, 2003).

The remaining crucial questions for course conducting are:

- How do our students and external participants perceive this online practice?

- How much will this online solution contribute to our teaching activities and the students' learning environment?

\section{The Subjective Experiences and Feedback Collected from the Students}

It was designed and undertaken a student survey to research the $1^{\text {st }}$ mentioned question. The survey was focused on user experiences and feedback from the students. The open- ended questions were used and all 37 students were asked to state their experience of using this course, in positive and negative aspects. The typically positive comments of their experiences are summarized in Table 1.

It is a clear indication that most students have appraised positively for the flexibility and freedom aspect of online learning (answer2 with 7 frequencies).

Based on their positive comments, it seems that students have well perceived this online solution and consider this solution as an opportunity to extend their flexibility and acces-

Table 1: Students' Positive Feedback ( $\mathrm{n}=37$ )

\begin{tabular}{|c|l|c|}
\hline Answer & \multicolumn{1}{|c|}{ Typically Positive Statement } & Frequency \\
\hline 1. & Good supplement to lectures & 3 \\
\hline 2 & Flexibility outside of campus & 7 \\
\hline 3 & Available curriculum and assignments timeless & 2 \\
\hline 4 & $\begin{array}{l}\text { No need for own notes and ever thing was digital- } \\
\text { ized and restored }\end{array}$ & 2 \\
\hline 5 & $\begin{array}{l}\text { Lots of available supplements through links and } \\
\text { attachments }\end{array}$ & 1 \\
\hline 6 & Fewer books to buy & 2 \\
\hline 7 & Nice to have opportunities to discuss online & 1 \\
\hline 8 & Convenience for distance learning & 1 \\
\hline 9 & $\begin{array}{l}\text { Good screen pictures and well organized icon } \\
\text { system }\end{array}$ & 3 \\
\hline 10 & Easy to navigate the courseware & 2 \\
\hline 11 & $\begin{array}{l}\text { Able to expand and explore knowledge off cam- } \\
\text { pus }\end{array}$ & 1 \\
\hline 12 & Nice way to submit assignments & 1 \\
\hline 13 & Nice way to overview the task for next week & \multicolumn{1}{|c|}{} \\
\hline 14 & Able to read the content before lectures & 2 \\
\hline
\end{tabular}


sibility for their enrolling for the courses.

Another remark was the focus of their comments: Their most comments seemed to focus on the accessibility for the supplements and extra reading sources, not so much on availability for online discussions (only two statements, see answer8 with 2 frequencies). This was understandable, since on campus students dominated this class, so they were able to meet each other on campus everyday, so there is no need for them to commence online discussions.

There were however, a number of negative comments received among the students' answers. Their representative statements are summarized in Table 2.

Reviewing these statements and comments, there seems to be no significant focus or emphasis to one particular direction of problems or issues (no answer or statement appears more than 4 times). The most common statements were related to uneasiness and fear for the virtual classroom (answer4 with 4 frequencies), rapid learning curve for the courseware (answer7 with 4 frequencies) and unwillingness for the online discussions (answer8 with 4 frequencies).

The two former statements were addressed to technical and training issues, while

Table 2: Students' Negative Feedback $(n=37)$

\begin{tabular}{|c|l|c|}
\hline Answer & Typically Negative Statement & Frequency \\
\hline 1 & Time consuming to write assignments on PC & 1 \\
\hline 2 & $\begin{array}{l}\text { A lot of work to read online than receiving } \\
\text { stuff in paper copies }\end{array}$ & 2 \\
\hline 3 & Poor feedback online & 1 \\
\hline 4 & $\begin{array}{l}\text { We should use a face-to-face classroom or a } \\
\text { black board }\end{array}$ & 4 \\
\hline 5 & Courseware's icons are confused & 2 \\
\hline 6 & Too many icons in courseware & 1 \\
\hline 7 & $\begin{array}{l}\text { Too many subsections and confused screen } \\
\text { display }\end{array}$ & 4 \\
\hline 8 & Discussions are useless for on campus students & 4 \\
\hline 9 & $\begin{array}{l}\text { Courseware was overemphasized than lecture } \\
\text { content }\end{array}$ & 1 \\
\hline 10 & \begin{tabular}{l} 
Tired of reading text on screen \\
\hline 11
\end{tabular} & Opening for cheating by online submission \\
\hline 12 & Difficult to submit assignments & 1 \\
\hline 13 & $\begin{array}{l}\text { The courseware works better for distance stu- } \\
\text { dents, not on campus }\end{array}$ & 2 \\
\hline 14 & We have poor computer skills, e.g. MS Excel & 1 \\
\hline 15 & $\begin{array}{l}\text { Poor training for exams, which required writ- } \\
\text { ing on paper. }\end{array}$ & 1 \\
\hline
\end{tabular}
the last one was a managerial issue. Indeed, most students were still feeling unsure about the online learning and the most critical obstacle seemed to be skills and familiarity to the courseware.

The previously mentioned field observation also confirmed this problematical issue. The observation revealed that most students followed this course through the traditional face-to-face lectures, aside to offered online lecturing arrangements.

Table 1 and Table 2 have presented the two contradictory aspects of use experiences. It seems to be difficult to combine these two aspects within one group or a class of students, and it seems not so easy to identifying the dominating aspect, merely from these subjective statements.

A complete analysis should combine both subjective observations and objective indications. The current study is also examining the course's database and analyzing the objective indications of the course process. 


\section{The Objective and Statistical Indications for the Course Activities}

Database and secondary data providing are the great advantage for an online course. Every document or a class interaction will be noticed and automatically restored in a course's database, which will be a perfect source of a course's statistical indications.

Like other topics, there are no unique answer for the standards and definitions regarding an online course's content, workload, and the quality criteria. There is usually a debatable issue for how much course content an online teacher shall convert online in order to meet the necessary requirement.

However, it will still be significant to summarize the statistical accounts of writing documents through the course. By such a summary, the "volume" of the process can be presented. It is probably not able to indicate the content and quality of the course, but still, it is a reasonable indicator for the workload.

Table 3 displays a summary of total course documents and their statistical distributions for different categories and groups. The table was divided into two major sections, one for students, thus online activities during the course, and another for teacher, thus online curriculum and content. The former reflects the levels of online class interactions, and the latter is an indication for how many documents an online teacher uses for the course.

A detailed look to the document frequency statistics on Table 3 is helping to demonstrating the following facts and conclusions:
Table 3: The Course Quantity Accounted By Document Frequency Statistics

\begin{tabular}{|l|c|l|c|}
\hline \multicolumn{1}{|c|}{ Students } & Frequency & \multicolumn{1}{c|}{ Teacher } & Frequency \\
\hline Assignments & 124 & Modules & 5 \\
\hline Discussions & 28 & Sections & 72 \\
\hline Comments & 42 & Project Tasks & 19 \\
\hline & & Guidelines & 13 \\
\hline & & Messages & 22 \\
\hline Total & 194 & Total & 131 \\
\hline Average student & 5 & Average teacher & 131 \\
\hline
\end{tabular}

- Totally, the online teacher has put great workload for the course planning and conducting processes (total 131 documents, in addition to a semester/15 weeks with a lecture intensity of 4 hours/week)

- The course planning process (5 modules, 72 sections and 19 project tasks) seems to require more resource than the conducting process (13 guidelines and 22 messages)

- Averagely, the students have a much lower level of their contributions and activities online than their online teacher (average student 5 against average teacher 131)

- Most student activities are focused on delivery of assignments (124 documents), which are duty tasks for them anyway.

- The students have a low level of online discussions, and their online participations are also much focused on replies and comments (42) than their initiative for the discussions (28).

Generally, the students for this online course seem not to be very active and engaged, though they also recognized the advantages of the approach. Their online activities seem to be appeared as their statements from table 2 than what they said in table 1. The field observation also indicated that most students, except that only external one, have all followed the course through the traditional face-to-face lectures as well. Few students expressed directly their reluctance to use this online solution and admitted that they used it only for their assignments delivery). 
It was mentioned early that most students had appraised positively for the flexibility and freedom aspect of online learning (answer2 with 7 frequencies in table 1). However, this indicator presented only their subjective opinions, not necessarily the real level of their online activities during the course.

The detailed analysis for the online activity $\log$ is an option to check such real online activities. Since the analysis was conducted from the secondary data, so there should be no way for misrepresenting the facts by opinions. In another word, what you see is what they did in the reality.

First, the definition of flexibility and freedom needs to be clarified and agreed. The common understanding for this aspect is anytime and anywhere, especially off working hours and off campus. There are three related terms are introduced with their definitions:

- Flexi-time: Any online visiting between 1601 and 0759 (outside of the standard Norwegian working hours 0800-1600). For instance, if one logs on and visits the course at 1823, it is accounted as a flexi-time online visit.

- Flexi-day: Any online visiting between 0001 on Saturday and 2359 on Sunday.

- Flexi-IP: Any registered online visiting IP address, which was located outside of the campus.

Table 4 illustrated an overview of online visiting $\log$, registered by flexi-time and flexi-day. As we can see, the online flexi-time visits account $23.71 \%$ (46 frequencies), a way below the half of total.

There is even no online flexi-day visit at all (0 frequency), which means students did never write anything to the course during the weekend.

A detailed analysis for Flexi-IP confirmed the same picture: Among the total 179 registered online visiting IP addresses, there are 137 located on campus and only 42 located exterior. The external IP addresses represented only $23.46 \%$, again, a way below the half of total.

This means most students were using the online option rarely off campus. They probably visited the course online, only when they were on campus and during the lecture days. The online flexibility and freedom were not fully applied and completely utilized.

Table 4: The Course Quantity Accounted By Document Statistics

\begin{tabular}{|c|c|l|c|}
\hline Daily time & Frequency & Weekday & Frequency \\
\hline 00:00:00 & 1 & Monday & 56 \\
\hline 03:00:00 & 1 & Tuesday & 31 \\
\hline 08:00:00 & 12 & Wednesday & 57 \\
\hline 09:00:00 & 13 & Thursday & 37 \\
\hline 10:00:00 & 14 & Friday & 13 \\
\hline 11:00:00 & 12 & Saturday & 0 \\
\hline 12:00:00 & 20 & Sunday & 0 \\
\hline 13:00:00 & 26 & & \\
\hline 14:00:00 & 22 & & \\
\hline 15:00:00 & 29 & & \\
\hline 16:00:00 & 13 & & \\
\hline 17:00:00 & 4 & & \\
\hline 18:00:00 & 4 & & \\
\hline 19:00:00 & 6 & & \\
\hline 20:00:00 & 13 & & \\
\hline 21:00:00 & 3 & & \\
\hline 23:00:00 & 1 & & \\
\hline Total & 194 & Total & 194 \\
\hline Flexi-time & 46 & Flexi-day & $0.00 \%$ \\
\hline Percentage & $23.71 \%$ & Percentage & \\
\hline
\end{tabular}

Summarizing the objective and statistical indications for online activities of this course, it shows a clear fact that online activities were less dominated compared with traditional face-to-face classroom teaching activities. 
Consequently, it is rather reasonable to define this online course conducting as a web supported course and learning environment. Actually, the course was indeed conducted heavily through the traditional face-to-face teaching hours, so the online courseware was mainly used as a supportive tool.

This practice sounds differently from the course's objectives stated early in this paper, namely flexibility, freedom and openings for on job training participants. It though contributes some advantages of an online solution, such as digitalizing of paperwork, information availability, and process log.

\section{Is It a Distinction of Course Organizing or Learning Style?}

Though there was a wish to conduct the current course in a web based learning environment, the real practice sound rather in a web supported environment. The distinction was noticeable, but the causal factor is still debatable: Is that a distinction of course organizing or learning style?

Reviewing the course intentions expected by the online teacher, it was meant and planned for conducting of a web based course in a web based learning environment. This was well illustrated by a relatively substantial part of the pre-lectured curriculum and syllabus online (total in 5 modules, 72 sections and 19 project tasks). The observations and analysis showed however, face-toface teaching activities dominated a major part of course conducting. Other online teaching related activities as discussions, consultations, teamwork and comments only contributed a minor part of total online activities in the course's virtual classroom.

Why online activities were down in a modest level? Why the students stated their positive opinions toward online learning, while they were actually reluctant to practice this option in their learning situations?

Though at the course beginning, it was intended and expected for fully online conducting and establishing a web based environment, it was also offered face-to-face teaching hours at the same time. This ambivalent approach and its effects need to be debated. There is also a need for clarifying the definitions of online teaching, consulting and their budgets for resources.

The students were apparently interested in using this online solution at the beginning, so they indicated positive attitudes toward this online arrangement (see Table 1). However, the technical obstacle and boringness of online reading might kill off their interests for the arrangement. It is also quite possible that the combination of unrealistic expectations, uncertainties and technical barriers among the users made users disappointed.

Though technical barriers could be a source to cause the negative reactions, the psychological effects of unrealistic expectations and uncertainties should not be neglected. Many probably expect online learning as a perfect or effortless solution. However, they often are not aware of the importance of sufficiently time or resource budgeting for their learning curve. As a result, they would therefore be disappointed after meeting certain troubles. Again, this would affect the users' attitudes toward the online solutions.

The students' answers (see Table 2, answer 2,4,13,15) also revealed that some of them still have a teacher-centered learning style. Web based environment requires on the other hand, a teamcentered learning style. So the attitude changing is another task. Even the teacher has created a web supported learning environment, it still needs learners' interests and engagement to fulfill the activities in this environment. The question of learning style (whether team-centered or teacher centered) seems to be a more important issue than the question of course organizing (whether web based or web supported). 


\section{Conclusions}

The following conclusions can be summarized for this course conducting:

- The course organizing seemed to be web based and fully face-to-face supported, and the learning style seemed to be teacher centered. The latter was not a modern teaching approach.

- Definitions of online teaching and learning should be addressed, identified and agreed at the beginning of this course conducting. By doing this, it would be easy to set up the goals and clarify the users' expectations.

- Course conducting should either focus on heavily online teaching or purely face-to-face teaching. The distinction and preference of online versus face-to-face teaching should be notified, determined and clarified in advance.

- The learners' learning style should be also discussed and defined. The students should be agreed to budget sufficient time for learning of online courseware. Moreover, they should be well prepared for meeting challenges and troubles during their online learning process.

For further study, a web based learning environment is clearly distinctive from a web supported one. Both environments need clear definitions. Their distinction needs to be debated and clarified. It is therefore an essential task for an online teacher to identify and clarify these distinctions, already in the online course planning stage, so that a most convenient and suitable learning environment can be determined and introduced.

\section{References}

Barrett, E., Levinson, D.A. \& Lisanti, S. (2001). The MIT guide to teaching web site design. Cambridge, Massachusetts \& London, England: MIT Press.

IBM Lotus software (2003). http://www.lotus.com/products/learnspace.nsf/wdocs/homepage

Jain, L.C., Howlett, R.J. Ichalkaranje, N.S. \& Tonfoni, G. (2002). Virtual environments for teaching \& learning. World Scientific Publishing Co.

Laerdal tunnel. (2000). http://home.no.net/lotsberg/data/norway/laerdal/tunnel.html

Naidu, S. (2003). Learning \& teaching with technology. Principles and practices. London and Sterling: Kogan Page.

Palloff, R. M., \& Pratt, K. (2003). The virtual student. A profile and guide to working with online learners. San Francisco: Jossey-Bass.

Selwood, I. D., Fung, A.C.W., \& O'Mahony, C.D. (2003). Management of education in the information age. The role of ICT. London: Kluwer Academic Publishers.

\section{Biography}

Hong Wu is an associate professor at Østfold University College, Faculty of Engineering in Sarpsborg, Norway. He received his $\mathrm{PhD}$ in project organization in 1992, at Norwegian University of Science and Technology (http://www.ntnu.no/indexe.php).

He is currently teaching these courses: Innovation and Product Analysis; Marketing Management. His research interests focus on topics of online teaching and learning, data analysis, and developing of online courses. For the last 10 years, he has also taught and worked with topics of Organizational Theories, Total Quality Management, Project Management and Cross-Cultural Analysis in Business Applications.

Contact phone: + 47691040 72/fax: + 4769104002

E-mail: hong.wu@hiof.no; http://www.ir.hiof.no/ hwu/Main/home.htm 